\title{
Purification, Characterization and Immunological Properties of the Capsular Polysaccharide of Pasteurella haemolytica Serotype T15: Its Identity with the K62 (K2ab) Capsular Polysaccharide of Escherichia coli and the Capsular Polysaccharide of Neisseria meningitidis Serogroup $\mathbf{H}$
}

\author{
By C. ADLAM, ${ }^{1 *}$ J. M. KNIGHTS, ${ }^{1}$ ANNE MUGRIDGE, ${ }^{1}$ \\ J. C. LINDON, ${ }^{2}$ JANET M. WILLIAMS ${ }^{2}$ AND J. E. BEESLEY ${ }^{3}$ \\ Departments of ${ }^{1}$ Bacteriology, ${ }^{2}$ Physical Chemistry and ${ }^{3}$ Electron Microscopy, \\ The Wellcome Research Laboratories, Beckenham, Kent BR3 3BS, UK
}

(Received 17 December 1984; revised 23 March 1985)

\begin{abstract}
Capsular polysaccharide from two strains of Pasteurella haemolytica serotype T15 was purified and characterized by chemical analysis and NMR spectroscopy. The polymer, a teichoic acid, proved to be very similar in structure to the capsular polysaccharide of $P$. haemolytica serotype T4 and identical to the previously described K62 (K2ab) capsular polysaccharide of Escherichia coli, and the capsular polysaccharide of Neisseria meningitidis serotype H, i.e. $\rightarrow$ (2-glycerol$3) \rightarrow($ phosphate $) \rightarrow(4-\alpha$-D-galactopyranose- 1$) \rightarrow$ with partial $O$-acetylation on the galactose residues. Electron microscopy with Protein A-gold labelled antisera showed that the polysaccharide was peripherally located on the surface of all three organisms. Chemical removal of $O$-acetyl groups from the polysaccharide yielded a structure identical to that previously described for $E$. coli $\mathrm{K} 2(\mathrm{~K} 2 \mathrm{a})$. Both $O$-acetylated and de- $O$-acetylated $P$. haemolytica $\mathrm{T} 15$ polymers, when absorbed on to sheep erythroyctes in passive haemagglutination assays, yielded identical antibody titres with sera raised against $P$. haemolytica $\mathrm{T} 15, E$. coli $\mathrm{K} 2$ or $N$. meningitidis $\mathrm{H}$ whole cells. De- $O$-acetylation of the Pasteurella polysaccharide influenced its precipitability with immune sera, but this could not be related to the absence of $O$-acetyl groups because the non-acetylated $E$. coli $\mathrm{K} 2$ polymer readily precipitated with a line of 'identity' with the acetylated $P$. haemolytica $\mathrm{T} 15$ polymer.
\end{abstract}

\section{INTRODUCTION}

In Great Britain, T serotypes of Pasteurella haemolytica (i.e. those that ferment trehalose) are responsible for systemic pasteurellosis of young sheep. This disease is most prevalent in post weaned animals aged between 6 months and 1 year and is frequently induced by stress (Gilmour, 1980). In an earlier paper (Adlam et al., 1985) we characterized the capsular polysaccharide of one of these serotypes, the T4. In the present study we used similar methods to purify and characterize the T15 capsular polysaccharide.

\section{METHODS}

Bacterial strains and growth conditions. P. haemolytica was maintained freeze dried, and grown in Pasteurella broth no. 7 (Wellcome). Strains CN4598 and CN8263 (Serotype T15) were obtained from Dr N. G. L. Gilmour (Moredun Institute, Edinburgh, UK). The majority of studies were done with strain CN4598 grown in a $200 \mathrm{ml}$ fermenter as previously described (Adlam et al., 1984). Confirmatory studies were done with CN8263 grown in a 51 fermenter containing 3.51 of the medium described above. The $\mathrm{OD}_{650}^{1 \mathrm{~mm}}$ of the final suspension was 8.4 for CN4598 and 11-3 for CN8263. Escherichia coli strain CN8271 serotype O6:K2:H1 (previously K2ac:H1) and $E$. coli strain CN8441 serotype O86:K62:H2 were obtained from Dr Barbara Jann (Max Planck Institut, Freiburg, FRG), and Neisseria meningitidis strain 1890 serogroup $\mathrm{H}$ from Dr F. E. Ashton (Bureau of Microbiology, The Laboratory Center for Disease Control, Ottawa, Ontario, Canada). Both organisms were grown overnight at $37^{\circ} \mathrm{C}$ 
on sheep blood agar plates $(7 \%, \mathrm{v} / \mathrm{v}$, in Oxoid blood agar base). E. coli was incubated in air and $N$. meningitidis in $10 \%(\mathrm{v} / \mathrm{v}) \mathrm{CO}_{2} /$ air.

Nuclear magnetic resonance (NMR) spectroscopy. Spectra were measured on $\mathrm{D}_{2} \mathrm{O}$ solutions with a Bruker WM360 instrument operating in the pulse-Fourier transform mode. Details of the ${ }^{1} \mathrm{H}$ and ${ }^{13} \mathrm{C}$ acquisition and processing parameters are given in the figure legends. Control of the two dimensional ${ }^{\prime} \mathrm{H}-{ }^{13} \mathrm{C}$ chemical shift correlation experiment was achieved with the Bruker microprogram HCCORR written for the instrument Aspect 2000 computer, utilizing the method of Bodenhausen \& Freeman (1977).

Electron microscopy. Bacteria were prepared, fixed and sectioned as previously described (Adlam et al., 1984). Immunocytochemical labelling of thin sections of the bacteria with Protein A-gold labelled antibody was done by the method of Beesley et al. (1982). Specimens were examined in a Philips 300 transmission electron microscope operating at $80 \mathrm{kV}$.

Production of antiserum. Rabbit antisera to $P$. haemolytica were raised by multiple intravenous injections of washed formalin-treated cells. Sheep antisera were raised against crude acetone precipitated polymer by intraperitioneal injection of antigen emulsified in incomplete Freund adjuvant (Wellcome). Both methods have been previously described (Adlam et al., 1984). Rabbit antiserum to a strain of E. coli serotype O86:K62 (K2ab) was generously provided by Dr Barbara Jann and that to $N$. meningitidis serogroup $\mathrm{H}$ by Dr F. E. Ashton.

Crossed immunoelectrophoresis. This was done on $5 \times 5 \mathrm{~cm}$ glass slides by the method of Axelsen et al. (1973). Each slide was covered with $3.3 \mathrm{ml}$ agarose (Sigma, Type I) dissolved in $0.06 \mathrm{M}$-Tris $/ \mathrm{HCl}(\mathrm{pH} 8 \cdot 6$ ) containing $1 \%$ (v/v) Triton X-100. Antigen $\left(5 \mu \mathrm{l} ; \mathrm{I} \mathrm{mg} \mathrm{m}^{-1}\right)$ was electrophoresed at $100 \mathrm{~V}$ for $45 \mathrm{~min}$ in the first dimension before running into agarose containing antiserum $(400 \mu \mathrm{l}$ antiserum per gel) in the second dimension ( $30 \mathrm{~V}$ for $18 \mathrm{~h}$ ). After washing the gels, precipitate arcs were visualized with Crowle's double stain (Polysciences, Northants., UK).

Bacterial agglutination. Single colonies were pickèd from overnight cultures of bacteria grown on blood agar, emulsified in isotonic saline and mixed with an equal volume of undiluted serum on a glass slide. A positive agglutination was observed to occur within $20 \mathrm{~s}$

Other methods. The preparation of crude and highly purified polysaccharides, de- $O$-acetylation, periodate treatment, amino acid analysis, molecular weight determination, saline extraction, immunodiffusion and passive haemagglutination were as described by Adlam et al. (1984); high pressure liquid chromatography (HPLC) and chemical analyses were as described by Adlam et al. (1985).

\section{RESULTS}

\section{Yield of extracted antigens}

The yield of crude acetone precipitate per litre of culture supernate was $0.89 \mathrm{~g}$ for strain $\mathrm{CN} 4598$. When this was further purified the yield of purified polymer was $14.4 \%$ by weight of crude precipitate. No attempt was made in these experiments to optimize yields of antigen by altering bacterial growth conditions.

\section{Physical and chemical characteristics}

The purified polymer was a white powder, freely soluble in water. Passing the polymer through a Sepharose 2B column gave a single peak, detectable at $206 \mathrm{~nm}$, of molecular weight approximating to that of blue dextran $\left(2 \times 10^{6}\right)$. No absorbance peaks were observed at $280 \mathrm{~nm}$. Chemical analysis showed the presence of phosphorus $(7.9 \%$ by weight $)$, hexose $(56 \%$ by weight with reference to a galactose standard), glycerol ( $16.3 \%$ by weight) and $O$-acetyl groups $(16.5 \%$ by weight with reference to an acetylcholine chloride standard). Assays for sialic acids, and Lowry protein gave essentially negative results. Nitrogen was absent on elemental analysis (Carlo Erba model $1106 \mathrm{CHN}$ analyser). A value of $3 \%$ by weight relative to galactosamine was obtained in the hexosamine assay but no nihydrin positive peaks were observed on amino acid analysis. The integrity of the polymer was destroyed by oxidation with periodate.

HPLC. Samples of de-O-acetylated polymer hydrolysed with $2 \mathrm{M}-\mathrm{HCl}$ for $4 \mathrm{~h}$ before dansylation gave a sharp peak when analysed by HPLC. This peak had almost the same retention time $(5.23 \mathrm{~min})$ as a dansylated galactose standard $(5.21 \mathrm{~min})$ but was clearly separable from glucose $(5.42 \mathrm{~min})$ and mannose $(5.98 \mathrm{~min})$ dansylated standards.

Optical configuration of galactose. The presence of D-galactose rather than L-galactose was confirmed by using D-galactose oxidase (Kurz \& Wallenfels, 1974). 


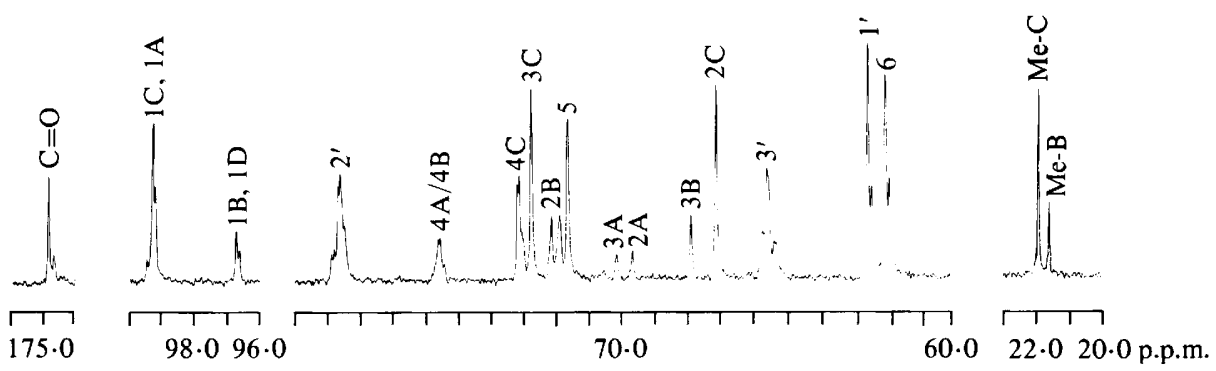

Fig. 1. $90.5 \mathrm{MHz}{ }^{13} \mathrm{C}$ NMR spectrum of the native polysaccharide of $P$. haemolytica serotype T15, strain CN8263. (32 K data points, broad band ${ }^{1} \mathrm{H}$ decoupled, $45^{\circ} \mathrm{C}, 20 \mathrm{kHz}$ spectrum width). A, de- $O$ acetyl, B, 2-O-acetyl, C, 3- $O$-acetyl, D, 2,3-di- $O$-acetyl. Numbers 1 to 6 refer to the sugar carbon atoms and $1^{\prime}, 2^{\prime}$ and $3^{\prime}$ refer to the glycerol carbon atoms. Reference: external dioxan at 67.4 p.p.m. $2 \mathrm{~Hz}$ line broadening.

\section{NMR spectroscopy}

The basic structure. The full ${ }^{13} \mathrm{C}$ NMR spectrum of the native polysaccharide produced from strain CN8263 is shown in Fig. 1. Peaks in the carbonyl region (175 p.p.m.) and near 21 p.p.m. indicated acetylation. As no nitrogen was detected by microanalysis, and as the ${ }^{13} \mathrm{C} N \mathrm{NMR}$ ruled out amino sugars, the acetylation must be due to $O$-acetyl substitution. No other peaks were observed in the aliphatic region of the spectrum thus ruling out the presence of lipid and protein in the sample. Inspection of the region around 100 p.p.m. (the anomeric carbon region) showed a minor peak to lower frequency at 96.5 p.p.m. indicating acetylation at $\mathrm{C} 2$ of the sugar. From the relative intensities of the $O$-acetyl methyl signal and the carbohydrate $\mathrm{CH}$ resonances, the extent of acetylation of the polymer was about $0.9 \mathrm{O}$-acetyl residues per repeating unit (see below for a more accurate assessment). Alkaline hydrolysis removed these $O$-acetyl groups and subsequent analysis was done on the de- $O$-acetylated polymer.

The ${ }^{13} \mathrm{C}$ NMR spectrum of this material confirmed a nine carbon repeating unit, some resonances showing spin coupling to a heteronucleus (presumed to be phosphorus because of the chemical analysis). The absence of amino or deoxy sugars was confirmed, and as chemical analysis had indicated the presence of a hexose and glycerol, these were thus present in equimolar proportions. The ${ }^{13} \mathrm{C}$ NMR spectrum of the de-O-acetylated material (strain $\mathrm{CN} 4598$ ) is shown in Fig. 2. Four of the peaks, three in the $\mathrm{CH}$ region and one in the $\mathrm{CH}_{2}$ region, exhibited doublet splitting or broadening caused by the spin interaction between ${ }^{13} \mathrm{C}$ and ${ }^{31} \mathrm{P}$. As such interactions are only observed over two or three bonds, this indicated that the phosphorus was part of a phosphodiester linkage. The $\mathrm{C} 1{ }^{13} \mathrm{C}$ signal was not coupled to phosphorus.

As previously described for the similar $P$. haemolytica T4 polymer (Adlam et al., 1985), there are ten possible general types of glycerol-phosphate-galactose polymer. Others, with more than one phosphate per repeating unit, were discounted as a result of the chemical analysis. Structures with $\mathrm{Cl}$ of the sugar linked to phosphate were also ruled out, since the sugar $\mathrm{Cl}$ carbon was not spin coupled to ${ }^{31} \mathrm{P}$. Three possible types remained:<smiles>COP(S)S</smiles>

I
II<smiles>CSP(C)O</smiles>

III

where $\mathrm{G}=$ glycerol, $\mathrm{S}=$ hexose and $\mathrm{P}=$ phosphate.

Identification of the sugar and of the anomeric nature of the linkage was from the ${ }^{1} \mathrm{H}$ NMR spectrum (Fig. 3). The signal at $5 \cdot 22 \delta$ was assigned to $\mathrm{H} 1$ and the coupling to $\mathrm{H} 2$ of $3.9 \mathrm{~Hz}$ indicated $\alpha$-glucose or $\alpha$-galactose. Similar spin decoupling experiments to those done on the T4 polysaccharide identified $\mathrm{H} 2$ and $\mathrm{H} 3$ and showed that the $\mathrm{H} 3-\mathrm{H} 4$ coupling was $3.0 \mathrm{~Hz}$, again 

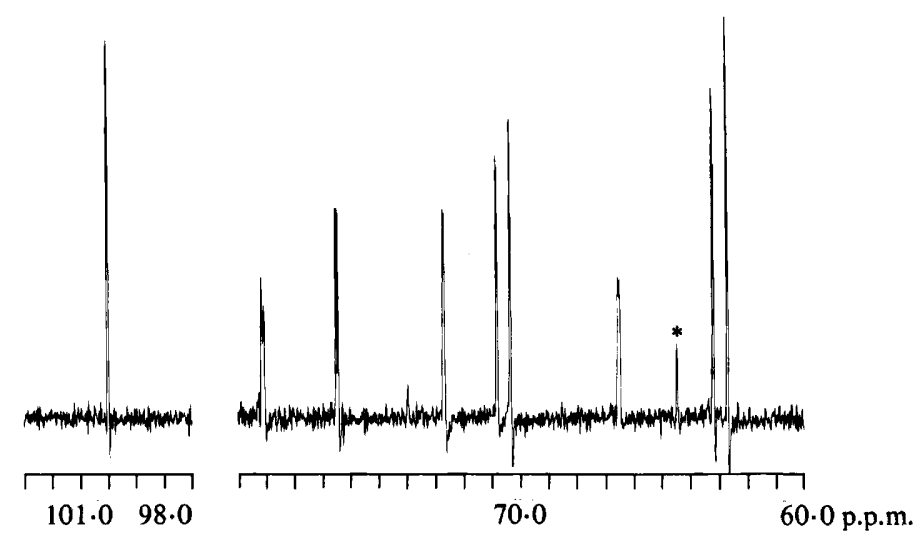

Fig. 2. $90 \cdot 5 \mathrm{MHz}^{13} \mathrm{C}$ spectrum of the de- $O$-acetylated polysaccharide of $P$. haemolytica strain CN4598. Lorentzian-Gaussian resolution enhanced, other conditions as for Fig. 1. (The asterisk denotes an unidentified impurity which was not present in other spectra of the de-O-acetylated polymer.)

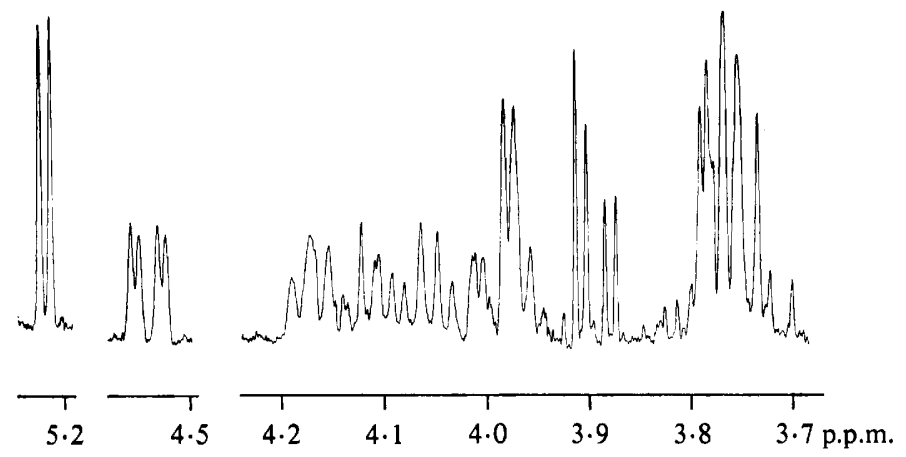

Fig. 3. $360 \cdot 13 \mathrm{MHz}{ }^{1} \mathrm{C}$ NMR spectrum of the de- $O$-acetylated polysaccharide of $P$. haemolytica strain CN4598. Lorentzian-Gaussian resolution enhanced, spectrum with $800 \mathrm{~Hz}, 4 \mathrm{~K}$ data points zero-filled to $32 \mathrm{~K}, 23^{\circ} \mathrm{C}$. Reference: internal acetone at $2 \cdot 225 \delta$.

confirming the sugar as $\alpha$-galactose. Irradiation of the signal at $4.54 \delta$ collapsed this $\mathrm{H} 3-\mathrm{H} 4$ coupling constant and identified the signal at $4.54 \delta$ as that from the galactose $\mathrm{H} 4$. The larger splitting on this signal of $9.3 \mathrm{~Hz}$ was not repeated on any other band in the ${ }^{1} \mathrm{H}$ NMR spectrum and was therefore assigned to an interaction with ${ }^{31} \mathrm{P}$. This eliminated stuctures of type II and showed that the phosphate was linked at $\mathrm{C} 4$. Knowing the sugar to be $\alpha$-galactose, it was possible to re-examine the $13 \mathrm{C}$ spectrum of the de-O-acetylated material. Here there were two ${ }^{31} \mathrm{P}$ coupled $\mathrm{CH}$ signals in the region 75-80 p.p.m. One could have arisen from the glycerol $\mathrm{CH}$ but at least one must have arisen from the galactose ring. As single $\mathrm{Cl}$ substituted $\alpha$-galactosides have no signals in this region this was further evidence for phosphate linked to the galactose at $\mathrm{C} 2, \mathrm{C} 3$ or $\mathrm{C} 4$. As the ${ }^{1} \mathrm{H}$ spectrum indicated ${ }^{31} \mathrm{P}$ coupling to $\mathrm{H} 4$, and allowing for only one $\mathrm{CH}_{2}$ ${ }^{13} \mathrm{C}$ signal to be perturbed from its position, the following were the only possible structures:

$$
\begin{array}{r}
\rightarrow(2 \text {-glycerol-3 }) \rightarrow\left(\mathrm{PO}_{4}\right) \rightarrow(4-\alpha-\mathrm{Gal}-7) \rightarrow \\
\rightarrow(\mathrm{X} \longrightarrow \alpha-\mathrm{Gal}-1) \rightarrow \\
(\text { glycerol-3 }) \rightarrow\left(\mathrm{PO}_{4}\right) \rightarrow(4)
\end{array}
$$

where III $a$ has $\mathrm{X}=$ carbon 2 of galactose and III $b$ has $\mathrm{X}=$ carbon 3 of galactose.

Structure III $a$ was discounted on the basis of the two ${ }^{31} \mathrm{P}$ coupled $\mathrm{CH}$ signals between 


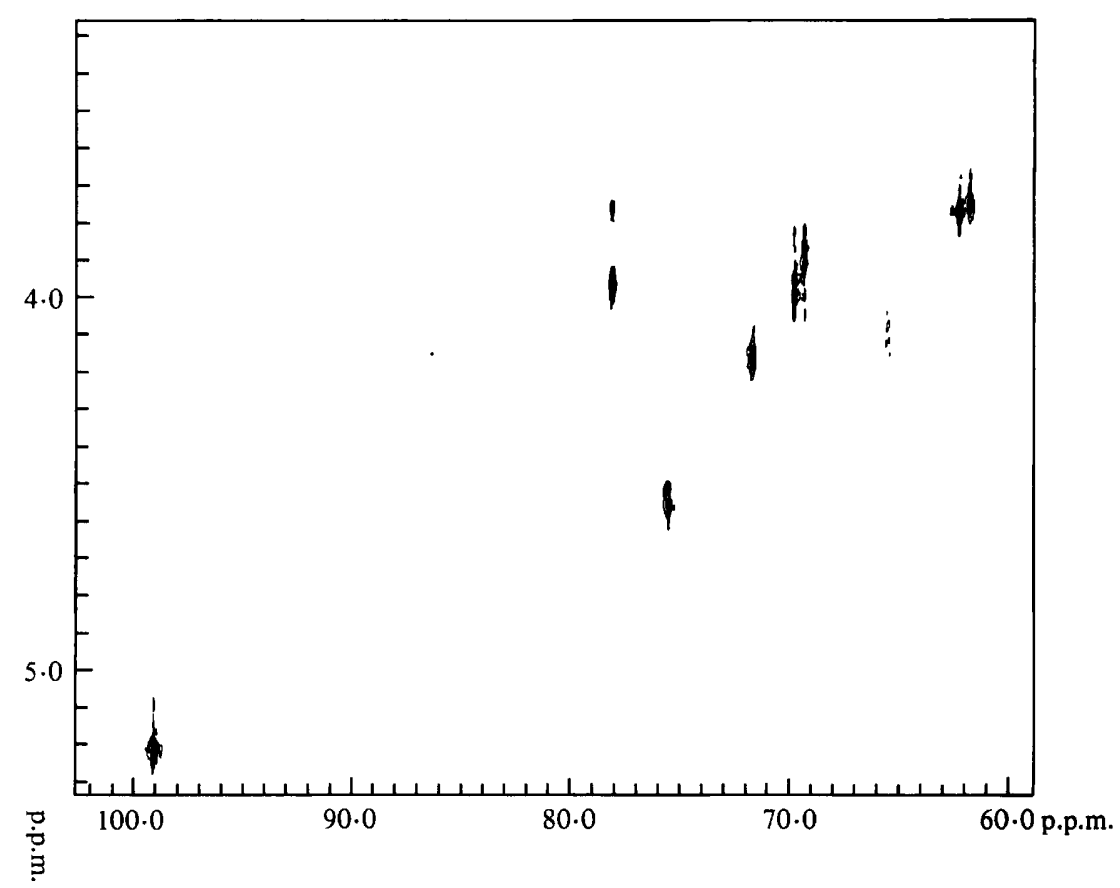

Fig. 4. Two dimensional ${ }^{1} \mathrm{H}-{ }^{13} \mathrm{C}$ chemical shift correlation contour plot of the de- $O$-acetylated polysaccharide of strain $C N 4598: 256$ experiments each of $2 \mathrm{~K}$ data points with spectrum width $3968 \mathrm{~Hz}$; 256 data points in the $\mathrm{Fl}$ interferrogram zero filled to $512 ;{ }^{1} \mathrm{H}$ spectrum width $747 \mathrm{~Hz} ; 5 \mathrm{~Hz}$ line broadening on F2 free induction decay; Lorentzian-Gaussian enhancement on F1 interferrogram.

75-80 p.p.m., as in this case only one would be in this range. This was confirmed by calculating the ${ }^{13} \mathrm{C}$ shifts using the substituent rules described by Poxton et al. (1978), which also showed that I and III $b$ could not be distinguished on the basis of ${ }^{13} \mathrm{C}$ chemical shifts and ${ }^{13} \mathrm{C}-{ }^{31} \mathrm{P}$ coupling constants. Structure III $a$ was also unlikely because it would not allow for any $2-O$ acetylation in the native polysaccharide.

To distinguish between the proposed structures a two dimensional ${ }^{1} \mathrm{H}-{ }^{13} \mathrm{C}$ chemical shift correlation experiment was done on the de- $O$-acetylated polymer. In this experiment the ${ }^{13} \mathrm{C}$ and ${ }^{1} \mathrm{H}$ chemical shifts for any $\mathrm{CH}_{n}$ group can be determined simultaneously and matched with each other (Bodenhausen \& Freeman, 1977). The spectrum is obtained in three dimensions and is usually plotted as a contour map with the ${ }^{13} \mathrm{C}$ chemical shifts along the horizontal axis and ${ }^{1} \mathrm{H}$ chemical shifts along the vertical axis. The coordinates of each peak therefore give the ${ }^{13} \mathrm{C}$ and ${ }^{1} \mathrm{H}$ chemical shifts for each $\mathrm{CH}$ or $\mathrm{CH}_{2}$ group. The resulting spectrum for the de-O-acetylated polysaccharide is shown in Fig. 4. Assignments already made in the ${ }^{1} \mathrm{H}$ spectrum by proton decoupling ( $\mathrm{H} 1, \mathrm{H} 2, \mathrm{H} 3$ and $\mathrm{H} 4)$, and assignments made in the ${ }^{13} \mathrm{C}$ spectrum on the basis of chemical shift $\left(\mathrm{Cl}, \mathrm{C} 6, \mathrm{Cl}^{\prime}\right.$ and $\left.\mathrm{C}^{\prime}\right)$, were used in the analysis of the $2 \mathrm{D}$ contour plot to give both ${ }^{1} \mathrm{H}$ and ${ }^{13} \mathrm{C}$ chemical shifts for $\mathrm{Cl}, \mathrm{C} 2, \mathrm{C} 3, \mathrm{C} 4$ and $\mathrm{C} 6$ of galactose, and $\mathrm{Cl}^{\prime}$ and $\mathrm{C}^{\prime}$ of glycerol. This left $\mathbf{C} 22^{\prime}-\mathrm{H}$ of glycerol, $\mathrm{C} 5-\mathrm{H}$ of galactose and the ${ }^{1} \mathrm{H}^{13} \mathrm{C}$ chemical shift pairs at $(3.97$, 79.0 p.p.m.) and (4.18, $71 \cdot 7$ p.p.m.) unassigned.

Clearly the ${ }^{13} \mathrm{C}$ chemical shift of $\mathrm{C} 3$ at 69.8 p.p.m. ruled out structure III $b$, and the assignments therefore of 79.0 p.p.m. and $3.97 \delta$ for the ${ }^{13} \mathrm{C}$ and ${ }^{1} \mathrm{H}$ shifts of the $\mathrm{C} 2{ }^{\prime}-\mathrm{H}$ group followed leaving $\mathrm{C} 5-\mathrm{H}$ at 71.7 p.p.m. and $4.18 \delta$ respectively for ${ }^{13} \mathrm{C}$ and ${ }^{1} \mathrm{H}$ shifts. The NMR data are summarized in Table 1 , and are in good agreement with those predicted, using substituent effect rules (Poxton et al., 1978), for structure I.

Position of $O$-acetylation. Having completely assigned the ${ }^{13} \mathrm{C}$ NMR spectrum it was now possible to evaluate the position and extent of $O$-acetylation. The acetyl methyl signal (Fig. 1) 
Table 1. NMR parameters for $P$. haemolytica $T 15$ polysaccharides

$\mathrm{C}$ and $\mathrm{H}$ refer to galactose, $\mathrm{C}^{\prime}$ and $\mathrm{H}^{\prime}$ refer to glycerol.

\begin{tabular}{|c|c|c|c|}
\hline & \multicolumn{3}{|c|}{ Chemical shift (p.p.m.) } \\
\hline & \multirow{2}{*}{$\begin{array}{l}\text { De- } O \text {-acetylated } \\
\text { polysaccharide }\end{array}$} & \multicolumn{2}{|c|}{ Native polysaccharide } \\
\hline & & $2-O-\mathrm{Ac}$ & $3-O-A \mathrm{c}$ \\
\hline $\mathrm{Cl}$ & $99 \cdot 1$ & 96.5 & $99 \cdot 1$ \\
\hline $\mathrm{C} 2$ & $69 \cdot 3$ & 71.7 or 71.9 & 66.9 \\
\hline $\mathrm{C} 3$ & $69 \cdot 8$ & $67 \cdot 7$ & $72 \cdot 5$ \\
\hline $\mathrm{C} 4$ & $75 \cdot 6(6 \cdot 1)^{*}$ & $75 \cdot 4$ & 73.0 \\
\hline $\mathrm{C} 5$ & $71 \cdot 7$ & $71 \cdot 4$ & $71 \cdot 4$ \\
\hline C6 & $61 \cdot 8$ & $61 \cdot 8$ & $61 \cdot 8$ \\
\hline $\mathrm{Cl}^{\prime}$ & $62 \cdot 2$ & $62 \cdot 3$ & $62 \cdot 3$ \\
\hline $\mathrm{C} 2$ & $78 \cdot 1(7 \cdot 4)^{*}$ & $78 \cdot 4$ & $78 \cdot 4$ \\
\hline $\mathrm{C}^{\prime}$ & $65 \cdot 5(4.9)^{*}$ & $65 \cdot 4$ & $65 \cdot 4$ \\
\hline $\mathrm{H} 1$ & $5.22\left(\mathrm{~J}_{12}=3.9\right)$ & & \\
\hline $\mathrm{H} 2$ & $3.89\left(\mathrm{~J}_{23}=10.4\right)$ & & \\
\hline H3 & $3.98\left(\mathrm{~J}_{34}=3.0\right)$ & & \\
\hline $\mathrm{H} 4$ & $4.54\left(\mathrm{~J}_{4-\mathrm{P}}=9 \cdot 3\right)$ & & \\
\hline H5 & $4 \cdot 18$ & & \\
\hline H6 & $3 \cdot 76 \dagger$ & & \\
\hline $\mathrm{Hl}^{\prime}$ & $3.78 \dagger$ & & \\
\hline $\mathrm{H} 2^{\prime}$ & 3.97 & & \\
\hline H3' & $4 \cdot 1 \uparrow$ & & \\
\hline
\end{tabular}

showed that two acetylation sites were present in the ratio of about $1: 3$. On the basis of the $\mathrm{Cl}$ signals of galactose the minor site of acetylation was at $\mathrm{C} 2$ of the galactose.

$O$-Acetylation gives significant downfield $\alpha$ substituent effects and upfield $\beta$ substituent effects on ${ }^{13} \mathrm{C}$ chemical shifts compared with de-O-acetyl chemical shifts. No such variation in ${ }^{13} \mathrm{C}$ chemical shifts of $\mathrm{C} 6, \mathrm{C} 5, \mathrm{Cl}^{\prime}$ or $\mathrm{C}^{\prime}$ was observed, and therefore no $O$-acetylation was present, at $\mathrm{C} 6$ of galactose or $\mathrm{Cl}^{\prime}$ of glycerol.

The possible sites of acetylation on the individual galactose residues in the native polysaccharide were at $\mathrm{C} 2$ or $\mathrm{C} 3$, or at both $\mathrm{C} 2$ and $\mathrm{C} 3$, or no $O$-acetylation. Chemical shift variation observed at $\mathrm{C} 1, \mathrm{C} 2, \mathrm{C} 3$ and $\mathrm{C} 4$ was compared with the corresponding chemical shifts in the de-O-acetylated polysaccharide, and the result was consistent with $O$-acetylation being present in the main of $\mathrm{C} 3$ but also at $\mathrm{C} 2$.

Minor resonances with chemical shifts corresponding to de- $O$-acetylation were also observed, but the presence of di-O-acetylation at $\mathrm{C} 2$ and $\mathrm{C} 3$ could not be excluded because the $\alpha$ - and $\beta$ substituent effects were cancelling or near cancelling for the chemical shifts of $\mathrm{C} 2$ and $\mathrm{C} 3$. Measurement of line intensities of the $\mathrm{C} 2$ resonance indicated $74 \% \mathrm{O}$-acetylation at $\mathrm{C} 3$, and $19 \%$ at $\mathrm{C} 2$, with $7 \%$ de-O-acetylated and/or di-O-acetylated at $\mathrm{C} 2$ and $\mathrm{C} 3$ in the native polysaccharide. The estimated error was $\pm 5 \%$. Small chemical shift changes were observed at other carbon resonances which were attributed to long range effects of $O$-acetylation at $\mathrm{C} 2$ and C3.

The ${ }^{13} \mathrm{C}$ NMR spectrum of the de- $O$-acetylated polysaccharide was identical to that kindly provided by Dr Barbara Jann (unpublished data) for the $E$. coli $\mathrm{K} 2$ polysaccharide. The spectrum of the $O$-acetylated polysaccharide was almost identical to that of the $E$. coli $\mathrm{K} 62$ polysaccharide, which is an acetylated form of the $\mathrm{K} 2$ polymer differing only slightly in the proportion of the acetylated and de-acetylated forms, but with 3-acetylation still predominating. The repeating unit structure deduced in the present work was therefore identical to the pyranose form given by them for the K62 polymer (Fischer et al., 1982).

A second preparation of polysaccharide from strain $\mathrm{CN} 8263$ produced a ${ }^{13} \mathrm{C}$ NMR spectrum 


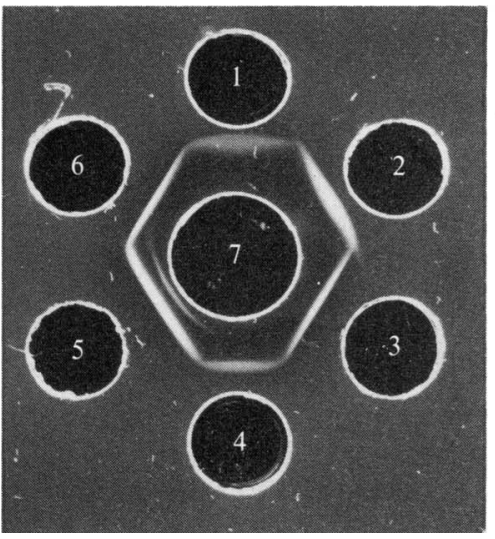

Fig. 5

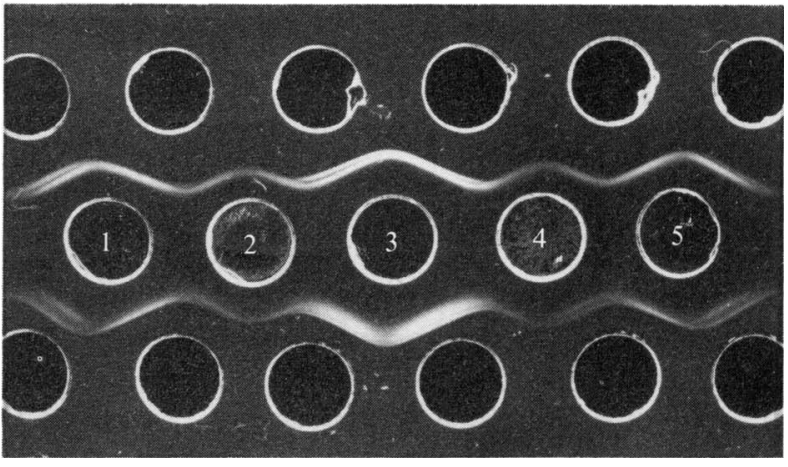

Fig. 6

Fig. 5. Immunodiffusion slide. Wells 1 and 4, undiluted crude saline extract of $E$. coli $\mathrm{K} 2$ (strain CN8271); well 2, undiluted crude saline extract of $P$. haemolytica T 15 strain CN4598; wells 3 and 6, purified $E$. coli 2 polymer $\left(1 \mu \mathrm{g} \mathrm{ml}^{-1}\right.$, gift of Dr B. Jann); well 5, purified $P$. haemolytica T15 polymer (strain CN4598, $1 \mu \mathrm{g} \mathrm{ml}^{-1}$ ); well 7, antiserum to $P$. haemolytica T15 (Moredun typing serum).

Fig. 6. Immunodiffusion slide. Top wells all contain purified $P$. haemolytica $\mathrm{T} 15$ polymer $\left(0 \cdot 25 \mu \mathrm{g} \mathrm{m}^{-1}\right.$, strain CN4598). Bottom wells all contain undiluted crude saline extract of $E$. coli K62 (strain CN8441). Centre wells all contain antisera raised against killed organisms as follows: $1, P$. haemolytica T15 typing serum (Moredun); 2, P. haemolytica T15 strain CN8263; 3, N. meningitidis H (gift of Dr F. E. Ashton); 4, E. coli K2 (gift of Dr B. Jann); 5, P. haemolytica T15 strain CN5494.

indicating a slightly different pattern of $O$-acetylation, namely $68 \%$ acetylation at $\mathrm{C} 3,22 \%$ at $\mathrm{C} 2$ and $10 \%$ de- $O$-acetyl and/or 2,3-di-O-acetyl.

In a preparation of native polysaccharide from strain $\mathrm{CN} 4598$, a total of six peaks was observed in the $\mathrm{C} 1$ region of the ${ }^{13} \mathrm{C}$ NMR spectrum. As acetylation at $\mathrm{C} 6$ or $\mathrm{Cl}$ could be discounted, these extra peaks demonstrated that acetylation in one residue can cause small chemical shift changes for carbons in adjacent residues. In this strain the $O$-acetylation pattern was significantly different, the approximate values for $O$-acetylation being $51 \%$ at $\mathrm{C} 3,21 \%$ at $\mathrm{C} 2$ and $27 \%$ de- $O$-acetyl and/or 2,3-di-O-acetyl.

In all preparations, 3-O-acetylated residues predominated but, as different batches varied somewhat in the proportions of the various $O$-acetylated forms, care must be taken in the interpretation of the significance of the pattern of $O$-acetylation.

\section{Serological properties}

The purified polymer did not elicit a specific antibody response when injected into two sheep. In contrast, partially purified crude acetone precipitated polymer was immunogenic. In a crossed immunoelectrophoresis experiment a single defined precipitate arc was observed in the presence of Triton-X 100 using an antiserum raised in a rabbit against inactivated whole $P$. haemolytica T15 cells. In immunodiffusion experiments, the purified polymer had identical immune precipitating properties to a purified sample of $E$. coli $\mathrm{K} 2$ polymer. Both purified polymers produced a major continuous line of 'identity' when diffused overnight against $P$. haemolytica T15, E. coli $\mathrm{K} 62$ or $N$. meningitidis $\mathrm{H}$ specific antisera. A second, continuous, less obvious inner line of precipitation (probably caused by the formation of a lower molecular weight polymer fraction) was also observed for both $P$. haemolytica $\mathrm{T} 15$ and $E$. coli $\mathrm{K} 2$ polymers (Fig. 5) in some gels. The T15 polymer did not precipitate with antisera raised against whole organisms of other $P$. haemolytica serotypes including T4. $P$. haemolytica T15 antigen gave a continuous precipitin line when diffused against $P$. haemolytica T15, E. coli $\mathrm{K} 2$ and $N$. meningitidis antisera on the same slide (Fig. 6). 


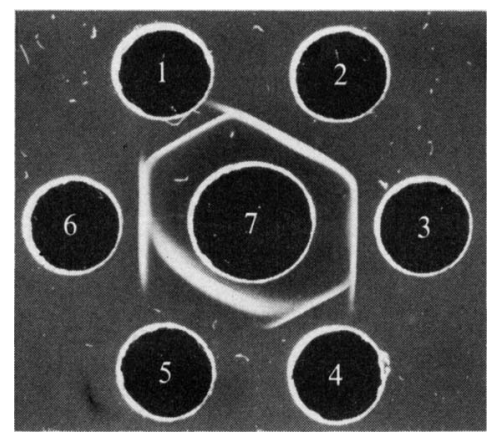

Fig. 7. Immunodiffusion slide. Wells 1 and 4 , purified $E$. coli $\mathrm{K} 2$ polymer $\left(0.5 \mu \mathrm{g} \mathrm{ml}^{-1}\right.$, gift of Dr B. Jann); well 2, purified $P$. haemolytica $\mathrm{T} 15$ polymer $\left(1 \mu \mathrm{g} \mathrm{ml}^{-1}\right)$ from strain CN4598; wells 3 and 6 , purified $P$. haemolytica T15 polymer $\left(1 \mu \mathrm{g} \mathrm{ml}^{-1}\right)$ from strain $\mathrm{CN} 8263$; well 5 , de-O-acetylated $P$. haemolytica $\mathrm{T} 15$ polymer $\left(1 \mu \mathrm{g} \mathrm{ml}^{-1}\right)$ from strain $\mathrm{CN} 4598$; well 7 , antiserum to $N$. meningitidis $\mathrm{H}$ (gift of Dr F. E. Ashton).

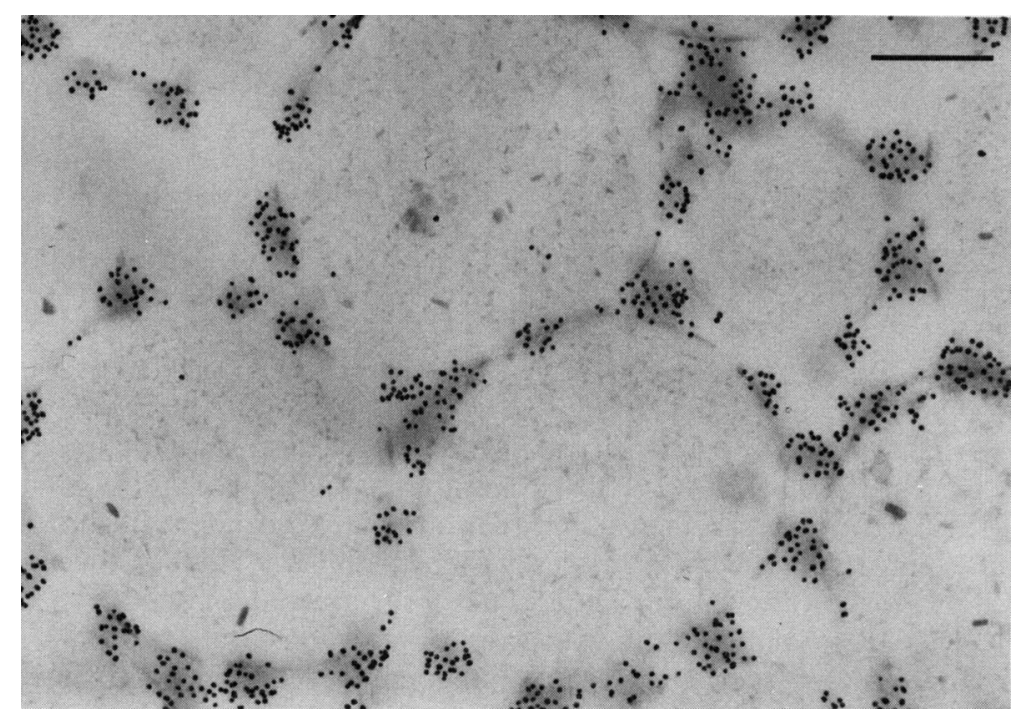

Fig. 8. Electron micrograph of sections of cells of $P$. haemolytica Ti5 strain CN4598 previously incubated with $P$. haemolytica T15 typing antiserum (Moredun Institute) and labelled with Protein Agold. Peripheral localization of label is apparent. Bar represents $0.5 \mu \mathrm{m}$.

Experiments with the de- $O$-acetylated T15 polymer produced a more diffuse precipitation line of 'partial identity' to that seen with native T15 polymer or with $E$. coli K2 polymer (Fig. 7).

In passive haemagglutination experiments, $P$. haemolytica $\mathrm{T} 15$ and de- $O$-acetylated $P$. haemolytica $\mathrm{T} 15$ and $E$. coli $\mathrm{K} 2$ polymers adhered to sheep erythrocytes at neutral $\mathrm{pH}$, and identical titres were recorded with these polymer coated erythrocytes when doubling dilutions of different antisera raised against whole cells of $P$. haemolytica T15, E. coli K62, E. coli $\mathrm{K} 2$ and $N$. meningitidis $\mathrm{H}$ were titrated.

In direct bacterial agglutination experiments, colonies of $P$. haemolytica $\mathrm{T} 15, E$. coli $\mathrm{K} 2$ and $N$. meningitidis $\mathrm{H}$ rapidly agglutinated when emulsified in the presence of antisera raised against any of these organisms. $P$. haemolytica serotypes other than T15 failed to agglutinate with these antisera. 


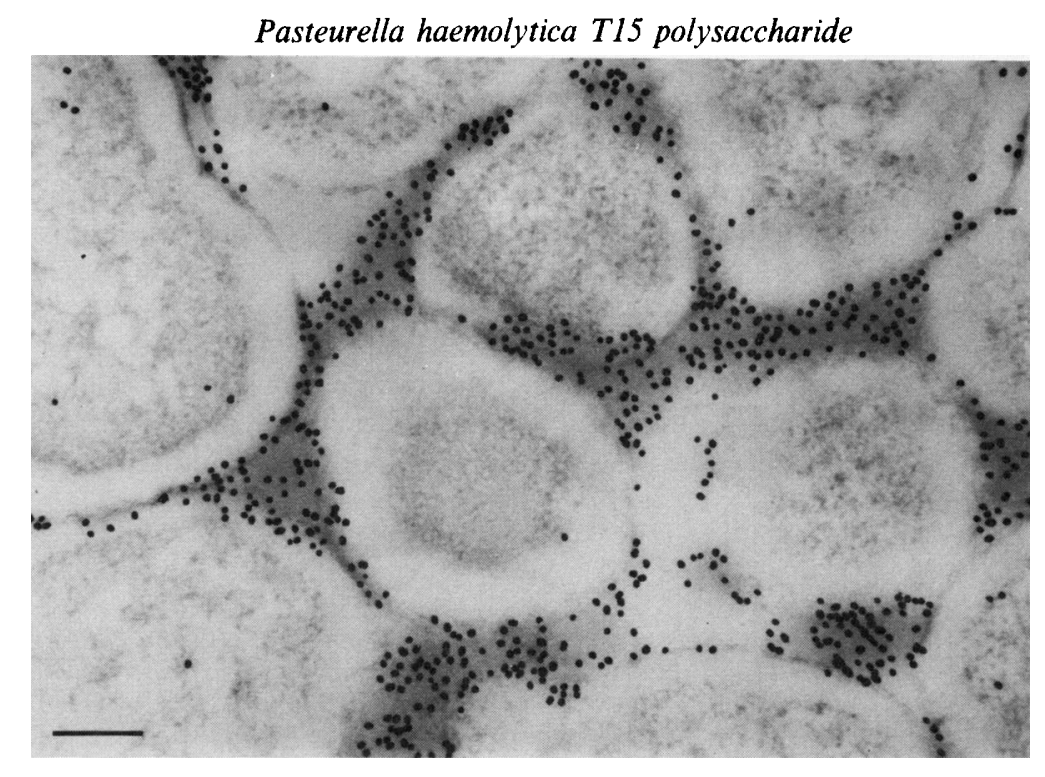

Fig. 9. Electron micrograph of sections of cells of $\boldsymbol{P}$. haemolytica T15 strain CN4598 previously incubated with antiserum raised against killed $E$. coli K62 organisms (gift of Dr B. Jann) and labelled with Protein A-gold. Bar represents $0.25 \mu \mathrm{m}$.

\section{Electron microscopy}

Protein A-gold labelling of rabbit and sheep antisera raised againt $P$. haemolytica T15, E. coli $\mathrm{K} 2$ and $N$. meningitidis $\mathrm{H}$ whole cells was used to demonstrate the peripheral localization of the T15 polysaccharide on $P$. haemolytica and the immunological relationship between the polysaccharides (Figs 8 and 9).

\section{DISCUSSION}

The capsular polysaccharide of $P$. haemolytica serotype T15 proved to be structurally identical to the pyranose form of the previously described K62 (K2ab) polysaccharide of $E$. coli (Jann \& Schmidt, 1980; Jann et al., 1980; Fischer et al., 1982). It is also identical to the capsular polysaccharide of serogroup $\mathrm{H} N$. meningitidis, which has recently been purified and characterized (Van der Kaaden et al., 1984; Michon et al., 1984). Thus both native and de- $O$ acetylated $\mathrm{T} 15$ polymers gave identical ${ }^{13} \mathrm{C}$ NMR spectra to those kindly provided for us by $\mathrm{Dr}$ B. Jann for her preparations of K62 (K2ab) and K2 (K2a) polymers. The native polymer gave an identical spectrum to those published by the two groups who have characterized the meningococcal polysaccharide.

The T15 polymer was also very similar to that of serotype T4 of $P$. haemolytica, differing from it only in having phosphate linked to the C6 of galactose rather than to C4 (Adlam et al., 1985). This difference was, however, sufficient to make the two $P$. haemolytica polymers immunologically non-cross reacting.

The fact that in passive haemagglutination experiments the $P$. haemolytica T15 polysaccharide behaved identically to the $\mathrm{K} 2$ polymer, which does not possess $O$-acetyl groups, (Dr Jann's results confirmed by us) demonstrates that these groups are not involved in erythrocyte adsorption at neutral $\mathrm{pH}$.

In immunodiffusion experiments with $P$. haemolytica $\mathrm{T} 15, E$. coli $\mathrm{K} 2$ and $N$. meningitidis $\mathrm{H}$ antisera, the immune precipitation observed with de- $O$-acetylated $\mathrm{T} 15$ polymer was less marked and more diffuse than that seen with native polymer. This could not be ascribed to the lack of $O$ acetyl groups on the polymer, however, because the non-acetylated $E$. coli $\mathrm{K} 2$ polymer gave precipitation equivalent to that seen with the $P$. haemolytica T15 polymer. 
These results are in general agreement with those of Larsen et al. (1980), who showed that both $O$-acetylated (K62) and de-O-acetylated (K2) E. coli polymers precipitated with antisera raised against organisms of either serotype. In contrast, Michon et al. (1984) showed that de-Oacetylation greatly reduced immune precipitation for their $N$. meningitidis $\mathrm{H}$ polysaccharide. Larsen et al. (1980) suggest that for $E$. coli $\mathrm{K} 2$ and $\mathrm{K} 62$, antibody specificities may be directed either towards $O$-acetyl groups or to the backbone polysaccharide. Differences in the specificities of individual polyclonal antisera tested could therefore explain the differences in precipitation profiles observed between $O$-acetylated and de- $O$-acetylated polymers.

The finding that an organism which produces systemic pasteurellosis in young sheep has an identical capsule to organisms of different genera which cause human urinary tract infections and meningitis respectively raises the possibility that these organisms may adhere to similar host target cell receptors.

\section{REFERENCES}

Adlam, C., Knights, J. M., Mugridge, A., Lindon, J. C., BAKer, P. R. W., Beesley, J. E., SPACEy, B., Craig, G. R. \& NagY, L. K. (1984). Purification, characterization and immunological properties of the serotype specific capsular polysaccharide of Pasteurella haemolytica (serotype A1) organisms. Journal of General Microbiology 130, 2415-2426.

Adlam, C., KNights, J. M., Mugridge, A., Lindon, J. C. \& Williams, J. M. (1985). Purification, characterization and immunological properties of the serotype specific capsular polysaccharide of Pasteurella haemolytica (serotype T4) organisms. Journal of General Microbiology 131, 387-394.

Axelsen, N. H., Krøll, J. \& Week, B. (1973). A manual of quantitative immunoelectrophoresis. Scandinavian Journal of Immunology 2, Supplement 1. Oslo: Universitets Forlaget.

Beesley, J. E., Orpin, A. \& Adlam, C. (1982). A comparison of immunoferritin, immuno-enzyme and gold-labelled Protein A methods for the localisation of capsular antigen on frozen thin sections of the bacterium Pasteurella haemolytica. Histochemical Journal 14, 803-810.

Bodenhausen, G. \& Freeman, R. (1977). Correlation of proton and carbon-13 spectra by heteronuclear two-dimensional spectroscopy. Journal of Magnetic Resonance 28, 471-476.

Fischer, W., SChMidT, M. A., JANN, B. \& JANN, K. (1982). Structure of the Escherichia coli K2 capsular antigen. Stereochemical configuration of the glycerophosphate and distribution of galactopyranosyl and galactofuranosyl residues. Biochemistry 21, 12791284.
Gilmour, N. J. L. (1980). Pasteurella haemolytica infections in sheep. Veterinary Quarterly 2, 191-197.

JANN, K. \& SCHMIDT, M. A. (1980). Comparative chemical analysis of two variants of the Escherichia coli $\mathrm{K} 2$ antigen. FEMS Microbiology Letters 7, 79-81.

JANN, K., JANN, B., SchmidT, M. A. \& VANN, W. F. (1980). Structure of the Escherichia coli $\mathrm{K} 2$ capsular antigen, a teichoic acid-like polymer. Journal of Bacteriology 143, 1108-1115.

KURZ, G. \& W ALlENFELS, K. (1974). D-Galactose UVassay with galactose dehydrogenase. In Methoden der Enzymatischen Analyse, 3rd edn, vol. II, pp. 12791282. Edited by H. U. Bergmeyer, Stuttgart: Verlag Chemie.

Larsen, J. C., Orskov, F., Orskov, I., Schmidt, M. A., JANN, B. \& JANN, K. (1980). Crossed immunoelectrophoresis and chemical structural analysis used for characterization of two varieties of Escherichia coli $\mathrm{K} 2$ polysaccharide antigen. Medical Microbiology and Immunology 168, 191-200.

Michon, F., Roy, R., Jennings, H. J. \& Ashton, F. E. (1984). Structural elucidation of the capsular polysaccharide of Neisseria meningitidis group H. Canadian Journal of Chemistry 62, 1519-1524.

Poxton, I. R., TARelli, E. \& Baddiley, J. (1978). The structure of C-polysaccharide from the walls of Streptococcus pneumoniae. Biochemical Journal 175, 1033-1042.

VAN DER KAADEN, A., VAN DOORN-VAN WAKEREN, J. I. M., Kamerling, J. P., Vliegenthart, J. F. G. \& TiEsJemA, R. H. (1984). Structure of the capsular antigen of Neisseria meningitidis serogroup H. European Journal of Biochemistry 141, 513-519. 